\title{
Assessing awareness and knowledge of hypertension in an at-risk population in the Karen ethnic rural community, Thasongyang, Thailand
}

This article was published in the following Dove Press journal:

International Journal of General Medicine

22 June 2012

Number of times this article has been viewed

\author{
Myo Nyein Aung ${ }^{1,2}$ \\ Thaworn Lorga ${ }^{2}$ \\ Janthila Srikrajang ${ }^{2}$ \\ Nongluk Promtingkran ${ }^{2}$ \\ Suchart Kreuangchai ${ }^{2}$ \\ Wilawan Tonpanya ${ }^{2}$ \\ Phatchanan Vivarakanon ${ }^{2}$ \\ Puangpet Jaiin ${ }^{2}$ \\ Nara Praipaksin ${ }^{3}$ \\ Apiradee Payaprom ${ }^{4}$ \\ 'Department of Public Health, \\ Graduate School of Medicine, \\ Juntendo University, Tokyo, Japan; \\ ${ }^{2}$ Boromarajonani College of Nursing \\ Nakhon Lampang (BCNLP), Lampang, \\ Thailand; ${ }^{3}$ Baan Rekati Health Station, \\ Thasongyang, Thailand; ${ }^{4}$ Thasongyang \\ Hospital, Thailand
}

Correspondence: Myo Nyein Aung Department of Public Health, Juntendo University School of Medicine, Hongo 2-I-I, Bunkyo-ku, Tokyo, I I3-842I, Japan

Tel +8I 35802 I049

Fax $+8 \mid 338140305$

or

Research Coordinating Unit, Boromarajonani College of Nursing Nakhon Lampang (BCNLP),

268 Parkam Road, Tambol Hauwieng,

Muang District, Lampang,

52000 , Thailand

Tel +66 54226254

Fax +6654225020

Email dr.myonyeinaung@gmail.com
Background: Hypertension is currently a global health concern. Rural and minority populations are increasingly exposed to risk factors as a result of urbanization, leading to hypertension and cardiovascular disease. We conducted a survey in the rural Karen community in Thasongyang District, Tak Province, Thailand, with the aims of determining: the distribution of blood pressure across different age groups; the prevalence of hypertension and other risk factors for cardiovascular diseases (CVDs), including diabetes, smoking, sedentary lifestyle, and excess alcohol use; knowledge and awareness of hypertension as a disease; and knowledge and awareness of risk factors for hypertension among the population at risk.

Methods: This was a community-based, cross-sectional survey of 298 rural Karen residents. A set of questionnaires assessing lifestyle-related health risk behaviors and awareness and knowledge of hypertension were used. Blood pressure, fasting plasma glucose, weight, height, and waist circumference were measured.

Results: Median systolic and diastolic blood pressures were 110 (range 100-120) $\mathrm{mmHg}$ and 70 (range 60-80) $\mathrm{mmHg}$, respectively. High blood pressure was observed in more than $27 \%$ of the population, with $15 \%$ being hypertensive and $12 \%$ being prehypertensive. Multinomial logistic regression analysis showed that people in the Karen community who were aware of hypertension were less likely to be current smokers (odds ratio [OR] 0.53, confidence interval [CI] 0.29-0.97) and those with primary school education were more likely to be aware of hypertension than those who did not have a primary school education (OR 6.5, CI 1.9-22.24). Overall, our survey showed that less than half of the Karen community had such knowledge and awareness.

Conclusion: It is urgently necessary to promote knowledge, awareness, and health literacy among the ethnic Karen tribes to prevent hypertension and associated CVDs.

Keywords: hypertension, Karen, smoking, awareness, knowledge, CVDs

\section{Introduction}

Hypertension is a worldwide risk factor for cardiovascular disease burden and mortality. ${ }^{1}$ It is a disease related to risky health behaviors, including smoking, poor diet, overweight and obesity, alcohol consumption, physical inactivity and occupational lifestyle. The perception of hypertension by the individual also plays an important role in changing lifestyle and risky health behaviors. ${ }^{2}$ Some risk factors for hypertension are modifiable, such as smoking, diet, and overweight, whereas some are not modifiable, such as old age and genetic predisposition. Changing modifiable risk factors may result in a reduced burden of hypertension, and people have to know that they are at risk of hypertension to be able to make voluntary lifestyle changes. However, there are many barriers to such awareness 
in rural and minority populations, including lack of formal school education, communication gaps, and inaccessibility to routine health education programs. Many studies have reported the prevalence of hypertension and its risk factors, but few have paid attention to the prevalence of knowledge and awareness about these risk factors in their study populations.

To perform this study, we approached the ethnic Karen minority in a rural Thai community, which is still naïve regarding health promotion interventions specifically designed for minority populations. The aims of this pilot study were to determine: the distribution of blood pressure across the age groups; the prevalence of hypertension and other risk factors for cardiovascular disease, such as diabetes, smoking, physical inactivity, and alcohol consumption; knowledge and awareness of hypertension; and knowledge and awareness of risk factors for hypertension among the at-risk population in the Karen community.

\section{Materials and methods}

The data for this study were collected in Karen village, which has a population of 700, in Thasongyang District, Tak Province, the most north-western district of Thailand, where the narrow Moei river forms the border between Myanmar and Thailand. It is a heavily forested and mountainous area, in which the study site village was located and composed of hamlets scattered on the hilltops. The study population comprised a convenience sample of 298 adult Karen Thai citizens aged over 30 years. Most of the participants were illiterate. The Karen is one of the hill tribes in Thailand, and constitutes one of the indigenous populations in Myanmar living along the Thai-Myanmar border. ${ }^{3}$

This was a cross-sectional study in which fasting plasma glucose levels, waist circumference, body weight, height, body mass index (BMI), and blood pressure were measured prospectively. Questionnaires administered by an interviewer were used to survey sociodemographic factors, lifestylerelated risk factors, and knowledge and awareness about hypertension.

The study was conducted between June 1, 2011 and September 30, 2011, and was approved by the ethics committee of Boromarajonani College of Nursing Nakhon Lampang, Lampang, Thailand. The aims of the study and its protocol were thoroughly explained to participants, and verbal informed consent was obtained. The analysis was planned and started in September 2011 and carried out until May 2012.

\section{Blood pressure}

Blood pressure was measured after at least 15 minutes of rest. Systolic and diastolic blood pressure was measured on two occasions, 15 minutes apart, for each study participant, by a community nurse using a sphygmomanometer. The first measurement was cross-checked with a second measurement to identify hypertensive individuals. Hypertension was defined as either systolic blood pressure $\geq 140 \mathrm{mmHg}$ or diastolic pressure $\geq 90 \mathrm{mmHg}$. ${ }^{4}$ Prehypertension was defined as a systolic pressure of $120-139 \mathrm{mmHg}$ or a diastolic pressure of $80-89 \mathrm{mmHg}$, consistent with the definition of higher than normal blood pressure in the Thai guidelines. ${ }^{4,5}$

\section{Fasting plasma glucose levels}

Fasting plasma glucose measurements were performed at the Thasongyang hospital laboratory after an 8-hour overnight fast. Prediabetes was defined as a fasting plasma glucose of $100-125 \mathrm{mg} \%$ and diabetes as $\geq 126 \mathrm{mg} \%{ }^{6,7}$

\section{Body mass index and waist circumference}

Body weight was measured by public health staff using a standard measuring scale. BMI was calculated as the ratio of body weight in kilograms divided by the square of height in meters $\left(\mathrm{kg} / \mathrm{m}^{2}\right)$. According to Asian and Thai cutoff values, a BMI of 23-25 is considered overweight, BMI 25-27 as preobesity, and $\mathrm{BMI} \geq 27$ as obesity. ${ }^{8-10}$ The abdominal waist circumference was measured at the umbilicus level using a measuring tape. ${ }^{11}$ Pregnant women and subjects with ascites were not included in the study. A waist circumference more than $80 \mathrm{~cm}$ was considered to be abnormal in women and more than $90 \mathrm{~cm}$ was considered to be abnormal in men, according to Thailand guidelines. ${ }^{6}$

\section{Lifestyle-related risk behaviors}

Current smokers were defined as being regular smokers at the time of survey. Exsmokers were those who had been smokers but had stopped smoking for at least 6 months prior to the survey. Nonsmokers were people who had never smoked. Current alcohol drinkers were those who had consumed any type of alcoholic drink regularly or irregularly during the previous year. Exdrinkers were those who had not consumed alcohol in the year prior to the survey. Teetotalers were those who had never consumed alcohol previously. We divided the participants into two groups according to their work-related physical activity. Most of the participants were farmers, and were classified as physically active. A sedentary lifestyle was defined as working seated for most working hours or being housebound with little physical movement.

\section{Questionnaires}

A set of questionnaires were developed by consensus among researchers at the Boromarajonani College of Nursing 
Nakhon Lampang and at the Thasongyang hospital. The questionnaires were carefully designed to assess the participants' knowledge of hypertension and their awareness of being at risk for hypertension. The questionnaires were written clearly in the Thai language and then translated into the Karen language by a researcher who could speak both languages fluently. The interviewer completed the questionnaires according to responses of the participants.

\section{Statistical analysis}

Continuous variables are presented as the mean and standard deviation or as the median and interquartile range based on normality of the data distribution. Stata version 11 (Stata Corporation, College Station, TX) was used for data management and analysis. Statistical significance was defined as $P<0.05$ with a $95 \%$ confidence interval (CI). Multinomial logistic regression analysis was used to assess the association between awareness of hypertension and smoking status and/or school education.

\section{Results}

\section{Demographic characteristics}

The sample population comprised Karen adults of mean age 45 (range 35-55) years. Median systolic blood pressure was $110 \mathrm{mmHg}$ and median diastolic blood pressure was $70 \mathrm{mmHg}$. The median fasting plasma glucose level was $88 \mathrm{mg} \%$. The average BMI of the sample population was 20.54. Female participants comprised $59 \%$ of the sample. More than $90 \%$ of participants lacked a formal school education. Most of the participants $(87.92 \%)$ were farmers (Table 1$)$.

\section{Blood pressure levels}

Median systolic blood pressure in the age groups $30-40$ years, 40-50 years, 50-60 years, and $>60$ years were 100 (interquartile range 100-110), 110 (100-120), 120 (100-128.5), and $120(100-130) \mathrm{mmHg}$, and diastolic blood pressure 70 (60-70), 70 (70-80), 70 (65-80), and 70 (70-80) mmHg, respectively (Figure 1). High blood pressure was observed in more than $25 \%$ of the population, with $12 \%$ being prehypertensive and $15 \%$ being hypertensive (Table 2). A higher range of systolic blood pressure was observed in individuals aged 50-60 years and those aged 60 years and older than in individuals aged younger than 40 years. Systolic and diastolic blood pressure for each age group is shown in Figure 1. Hypertension was found in $16 \%$ of males and $14 \%$ of females. The prevalence of hypertension in the different age groups was $9 \%$ in those aged $30-40$ years, $16 \%$ in those aged $40-50$ years, $17 \%$ in those aged $50-60$ years, and $23 \%$ in those older than 60 years.
Table I Characteristics of the sample population $(n=298)$

\begin{tabular}{|c|c|c|}
\hline Characteristic & $\mathbf{n}$ & Percentage \\
\hline Number & 298 & \\
\hline Age (years) & $45(35-55)$ & \\
\hline \multicolumn{3}{|l|}{ (median, IQR) } \\
\hline Systolic BP & $110(100-120)$ & \\
\hline \multicolumn{3}{|l|}{ (median, IQR) } \\
\hline Diastolic BP & $70(60-80)$ & \\
\hline \multicolumn{3}{|l|}{ (median, IQR) } \\
\hline BMI $\left(\mathrm{kg} / \mathrm{m}^{2}\right)$ & $20.54(18.73-22.89)$ & \\
\hline \multicolumn{3}{|l|}{ (median, IQR) } \\
\hline Fasting plasma glucose & $88(8 I-95)$ & \\
\hline \multicolumn{3}{|l|}{ (mg\%, median, IQR) } \\
\hline \multicolumn{3}{|l|}{ Age group, years } \\
\hline $30-40$ & 116 & 38.93 \\
\hline $40-50$ & 66 & 22.15 \\
\hline $50-60$ & 64 & 21.48 \\
\hline$>65$ & 52 & 17.45 \\
\hline \multicolumn{3}{|l|}{ Gender } \\
\hline Male & 122 & 40.94 \\
\hline Female & 176 & 59.06 \\
\hline \multicolumn{3}{|l|}{ Race } \\
\hline Karen & 298 & 100 \\
\hline \multicolumn{3}{|l|}{ Education } \\
\hline School education & 27 & 9.31 \\
\hline No school education & 263 & 90.69 \\
\hline \multicolumn{3}{|l|}{ Occupation } \\
\hline Farmers & 262 & 87.92 \\
\hline Daily wage earner & 13 & 4.36 \\
\hline Government service & 1 & 0.35 \\
\hline Housewife & 10 & 3.36 \\
\hline Unknown & 12 & 4.03 \\
\hline
\end{tabular}

Abbreviations: $\mathrm{BMI}$, body mass index; $\mathrm{BP}$, blood pressure; IQR, interquartile range.

\section{Cardiometabolic risk factors and health risk behaviors}

Fasting plasma glucose screening revealed that $16.17 \%$ of the population had abnormally high fasting plasma glucose levels, with $3.96 \%$ in the diabetic range and $13.09 \%$ in the prediabetic range. Thirty percent of the study population had a BMI above 23 which is the threshold for overweight in the Thai guidelines, and 17.79 had a BMI over 25. Persons at risk

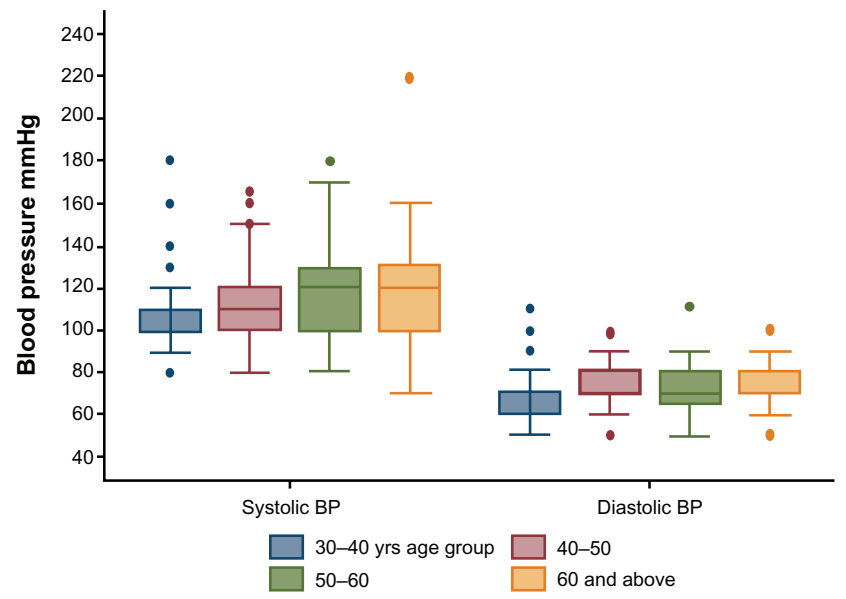

Figure I Distribution of systolic and diastolic blood pressure by age group in the sample population of the Karen ethnic community, Thasongyang, Thailand $(n=298)$. 
Table 2 Distribution of risk factors for hypertension and knowledge of risk factors in the at-risk population $(n=298)$

\begin{tabular}{|c|c|c|c|c|}
\hline \multirow{2}{*}{$\begin{array}{l}\text { Questionnaires } \\
\text { Risk factors and categories }\end{array}$} & \multirow[t]{2}{*}{$\mathbf{n}$} & \multirow[t]{2}{*}{$(\%)$} & \multicolumn{2}{|c|}{ Assessment of knowledge* } \\
\hline & & & $\begin{array}{l}\text { Those who knew they } \\
\text { were at risk/correct } \\
\text { answer } \\
(\%)\end{array}$ & $\begin{array}{l}\text { Those who did not } \\
\text { know they were at } \\
\text { risk/incorrect answer } \\
\text { (\%) }\end{array}$ \\
\hline \multicolumn{5}{|l|}{ "Smoking people tend to have hypertension" } \\
\hline Overall & 298 & & 54.03 & 38.59 \\
\hline Current smoker & 202 & 67.79 & 55.45 & 38.12 \\
\hline Exsmoker & 20 & 6.71 & 35.00 & 55.00 \\
\hline Nonsmoker & 67 & 22.48 & 59.70 & 38.81 \\
\hline \multicolumn{5}{|c|}{ "Overweight people are more likely to have hypertension" } \\
\hline Overall & 298 & & 51.68 & 40.27 \\
\hline $\mathrm{BMI} \geq 25$ & 53 & 17.79 & 54.72 & 40.48 \\
\hline $\mathrm{BMI} \geq 23$ and $<25$ & 35 & 11.74 & 34.29 & 48.57 \\
\hline $\mathrm{BMI}<23$ & 210 & 70.47 & 53.81 & 33.96 \\
\hline Within normal WC & 264 & 88.59 & 54.17 & 37.88 \\
\hline Abnormal WC & 34 & $\mathrm{II} .4 \mathrm{I}$ & 32.35 & 58.82 \\
\hline \multicolumn{5}{|l|}{ "Drinking alcohol is a risk factor for hypertension" } \\
\hline Overall & 298 & & 52.01 & 40.27 \\
\hline Current drinker & 147 & 49.33 & 51.7 & 40.14 \\
\hline Exdrinker & 38 & 12.75 & 44.74 & 50.00 \\
\hline Teetotaler & 103 & 34.56 & 57.28 & 39.81 \\
\hline \multicolumn{5}{|l|}{ "Old age is a risk factor for hypertension" } \\
\hline Overall & 298 & & 41.61 & 51.01 \\
\hline Age $30-40$ years & 116 & 38.93 & 43.10 & 48.28 \\
\hline Age $40-50$ years & 66 & 22.15 & 39.39 & 54.55 \\
\hline Age $50-60$ years & 64 & 21.48 & 45.31 & 48.44 \\
\hline Age $>60$ years & 52 & 17.45 & 36.54 & 55.77 \\
\hline \multicolumn{5}{|l|}{ "I am at risk of hypertension" } \\
\hline Overall & 298 & & 5.03 & 87.58 \\
\hline $\mathrm{BP}<120 / 80 \mathrm{mmHg}$ & $216^{\#}$ & 72.48 & 3.7 & 90.74 \\
\hline BP I20/80-139/89 mmHg & 37 & 12.42 & 10.81 & 72.97 \\
\hline $\mathrm{BP} \geq 140 / 90 \mathrm{mmHg}$ & 45 & 15.10 & 6.67 & 84.44 \\
\hline \multicolumn{5}{|l|}{ "I am at risk of diabetes" } \\
\hline Overall & 298 & & & \\
\hline FPG $<100 \mathrm{mg} \%$ & 249 & 85.56 & 2.01 & 89.16 \\
\hline FPG $\geq 100-125 \mathrm{mg} \%$ & 39 & 13.09 & 2.56 & 92.31 \\
\hline $\mathrm{FPG} \geq 126 \mathrm{mg} \%$ & 10 & 3.36 & 0 & 100 \\
\hline "Hypertension is a noncommunicable disease" & 276 & & 22.46 & 77.54 \\
\hline "Hypertension needs lifelong treatment" & 276 & & 32.61 & 67.39 \\
\hline "Normal blood pressure I20/80 mmHg" & 274 & & 44.53 & 55.47 \\
\hline "Hypertension means $B P \geq 140 / 90 \mathrm{mmHg}$ " & 276 & & 43.48 & 56.52 \\
\hline "High-salt diet can cause hypertension" & 276 & & 57.61 & 42.39 \\
\hline "Stress can lead to hypertension" & 274 & & 55.11 & 44.89 \\
\hline "Excess coffee and tea can lead to hypertension" & 276 & & 42.39 & 57.61 \\
\hline "Regular exercise can prevent hypertension" & 276 & & 44.57 & 55.43 \\
\hline
\end{tabular}

Notes: *Know and do not know percentages were calculated based on a sample of 298 . Response rate was not $100 \%$ in all questionnaires. Missing responses were analyzed as missing. Response rate was more than $93 \%$ on average. "Three of 216 persons with normal blood pressure had controlled hypertension on medical treatment. Abbreviations: BP, blood pressure, FPG, fasting plasma glucose; WC, waist circumference.

by virtue of a BMI above 23, fasting plasma glucose more than $100 \mathrm{mg} \%$, systolic blood pressure above $120 \mathrm{mmHg}$, and diastolic pressure above $80 \mathrm{mmHg}$, are identified in the two-way spike diagram shown in Figure 2. Being farmers and manual workers, they had a physically active lifestyle. Only
$3.72 \%$ reported a sedentary lifestyle and nearly $70 \%$ of the population were smokers (Figure 3). The smoking rate was $76.23 \%$ in males and $61.93 \%$ in females. More than half of the population consumed alcohol (61.48\% males and $40.91 \%$ females). 

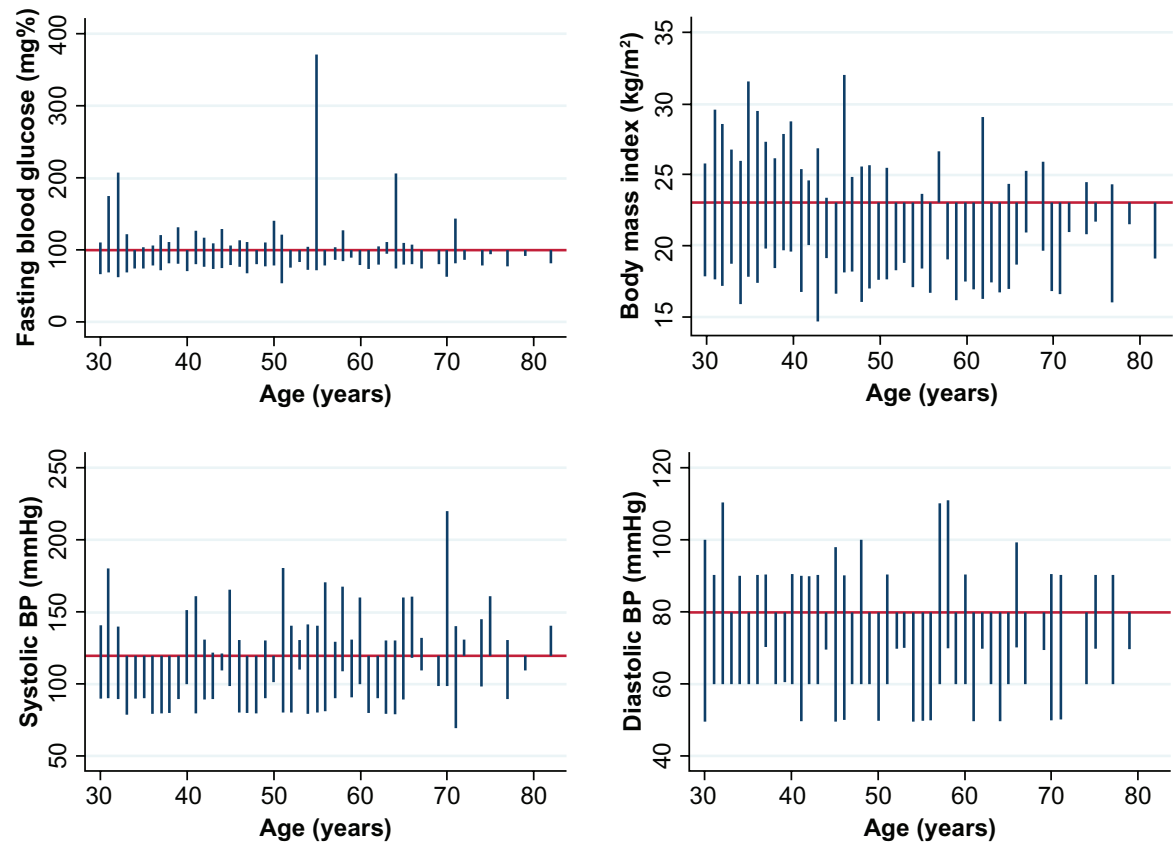

Figure 2 Two-way spike plot diagram showing distribution of persons at risk according to blood pressure, fasting blood glucose, and body mass index in the sample population, $(n=298)$.

Notes: The cutoffs were a body mass index of $23 \mathrm{~kg} / \mathrm{m}^{2}$, fasting blood sugar of $100 \mathrm{mg} \%$, systolic blood pressure $120 \mathrm{mmHg}$ and diastolic blood pressure $80 \mathrm{mmHg}$.

\section{Awareness of hypertension}

Almost half of the participants responded that they had never heard of hypertension, more than $80 \%$ answered that they did not fully understand what hypertension was, $97 \%$ did not know if they had high blood pressure, $91.96 \%$ did not notice whether their relatives had hypertension, and $95 \%$ thought they were not at risk of hypertension (Figure 4). Only 20\% of participants had had their blood pressure checked in the previous year. Table 2 summarizes risk factor exposure in the study sample and knowledge about risk factors in the at-risk population.

\section{Smoking}

In total, $67.79 \%$ of participants were current smokers, $6.71 \%$ were exsmokers and $23.18 \%$ were nonsmokers, as shown in Figure 3. Among the current smokers, 38.12\% did not know that smoking was a risk factor for hypertension (Table 2).

\section{Overweight}

The survey of BMI showed that $17.79 \%$ had a BMI $>25$ and $11.74 \%$ had a BMI of 23-25. Forty percent of overweight individuals did not know that being overweight is a risk factor for hypertension (Table 2).

\section{Alcohol consumption}

For alcohol consumption, $49.33 \%$ of the sample admitted to being current drinkers and $12.75 \%$ reported being exdrinkers
(Figure 3). More than $40 \%$ did not know that alcohol is a risk factor for hypertension (Table 2).

\section{Advancing age}

More than $40 \%$ of participants were over 40 years of age. However, more than half of this age group did not know that advancing age is a risk factor for hypertension (Table 2).

\section{Diabetes}

On screening, $16.45 \%$ of the participants had abnormally high fasting plasma glucose levels. All participants in the diabetic range of fasting plasma glucose and $92.31 \%$ of participants with prediabetes did not know that they were at risk of diabetes.

\section{Blood pressure and disease-specific knowledge about hypertension}

High blood pressure was detected in $27.52 \%$ of participants, with $15.10 \%$ being hypertensive and $12.42 \%$ being prehypertensive. Most of the hypertensive (84.44\%) and prehypertensive $(72.97 \%)$ participants did not know that they had hypertension risk. (Table 2). Most (77.54\%) did not know that hypertension is a non-communicable disease or that it needs lifelong treatment $(67.39 \%)$. About half of the sample population lacked disease-specific knowledge about hypertension, such as values in the normal and high blood pressure 


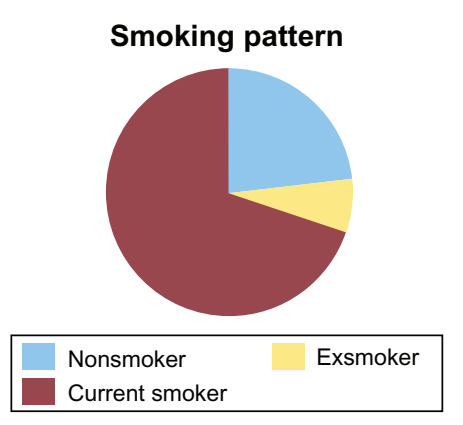

Occupational lifestyle

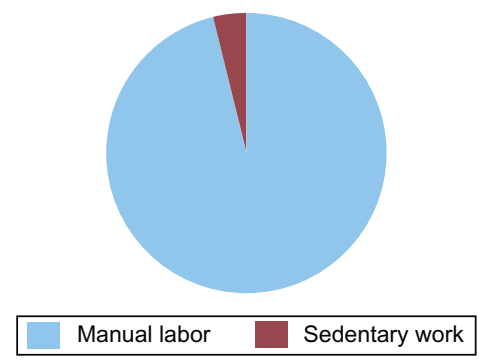

\section{Alcohol consumption pattern}

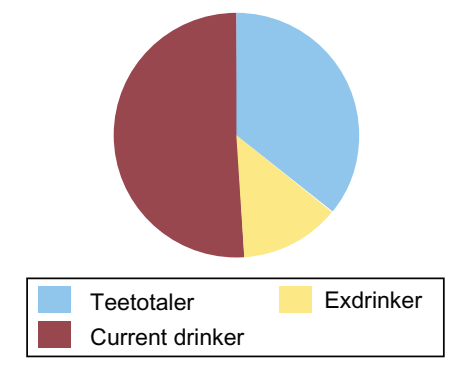

Physical activity related to work

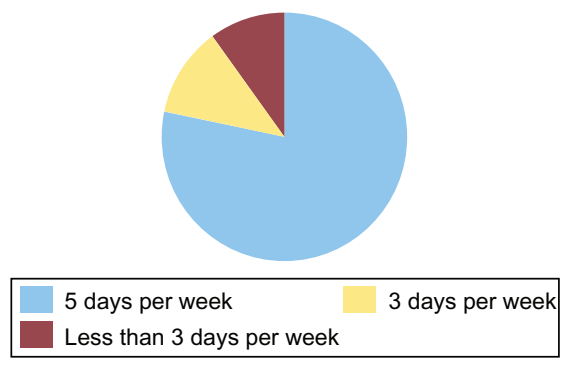

Figure 3 Health risk behavior and lifestyle-related risk factors among the Karen ethnic population in Thasongyang, Thailand $(\mathrm{n}=298)$.

Notes: Current smokers comprised $67.79 \%$ of the overall population, current alcohol drinkers comprised $49.33 \%, 3.7 \%$ had a sedentary occupation, and $10.4 \%$ reported low physical activity ( ie, physical activity until sweating on fewer than three days per week).

range or the risk factors for hypertension, such as a high-salt diet, excess coffee and tea, and a stressful lifestyle (Table 2). Most members of the Karen community had a physically active occupation. However, $55.43 \%$ of the participants did not know that regular exercise helps to prevent hypertension.

\section{Association between schooling and health education on hypertension}

The question "have you ever heard of hypertension?" was responded to with "yes" by $57.28 \%$ of participants and "no" by $41.82 \%$ (Figure 4 ). Further analysis by multinomial logistic regression analysis showed that people who had heard of hypertension were less likely to be current smokers (odds ratio [OR] 0.53, CI 0.29-0.97, Table 3). An answer of "ever heard" or "never heard" of hypertension was significantly associated with attainment of primary school education. A school education was positively associated with health education about hypertension (OR 6.5, CI 1.9-22.2, Table 4).

\section{Discussion}

Hypertension is a growing global health problem, ${ }^{12}$ with a rapidly increasing prevalence in developing countries in Asia. ${ }^{13,14}$ Hypertension is one of the major cardiovascular diseases, and is a major risk factor for other cardiovascular diseases, such as stroke and ischemic heart disease. ${ }^{14,15}$ We conducted a survey of blood pressure, prevalence of hypertension, risk factors for cardiovascular disease, and people's awareness of those risk factors in the rural Karen community in Thasongyang District, Thailand.

Nowadays, the Thai community is exposed to a variety of health risk factors, such as obesity (BMI $\geq 25$ in $34.2 \%$ ), insufficient physical inactivity (19.2\%), smoking $(39.8 \%$ in males and $3.4 \%$ in females), and alcohol consumption (32\%), leading to an increasing prevalence of hypertension and cardiovascular disease. ${ }^{16,17}$ Being less urbanized, the prevalence of these risk factors in the Karen community was expected to be low. We observed a lower prevalence

Table 3 Influence of health education about hypertension on smoking risk behavior

\begin{tabular}{|c|c|c|c|c|c|}
\hline \multirow{2}{*}{$\begin{array}{l}\text { Health awareness } \\
\text { "I have ever heard } \\
\text { of hypertension" }\end{array}$} & \multirow[t]{2}{*}{$\mathbf{n}$} & \multicolumn{2}{|c|}{ Exsmokers } & \multicolumn{2}{|c|}{ Current smoker } \\
\hline & & $\%(n)$ & OR $(95 \% \mathrm{Cl})$ & $\%(n)$ & OR (95\% Cl) \\
\hline No & 116 & $7.76(9)$ & 1.00 & $75(87)$ & 1.00 \\
\hline Yes & 156 & $6.4 I(10)$ & $0.50(0.17-1.43)$ & $65.38(102)$ & $0.53(0.29-0.97)$ \\
\hline
\end{tabular}

Abbreviations: OR, odds ratio by multinomial logistic regression; $\mathrm{Cl}$, confidence interval. 


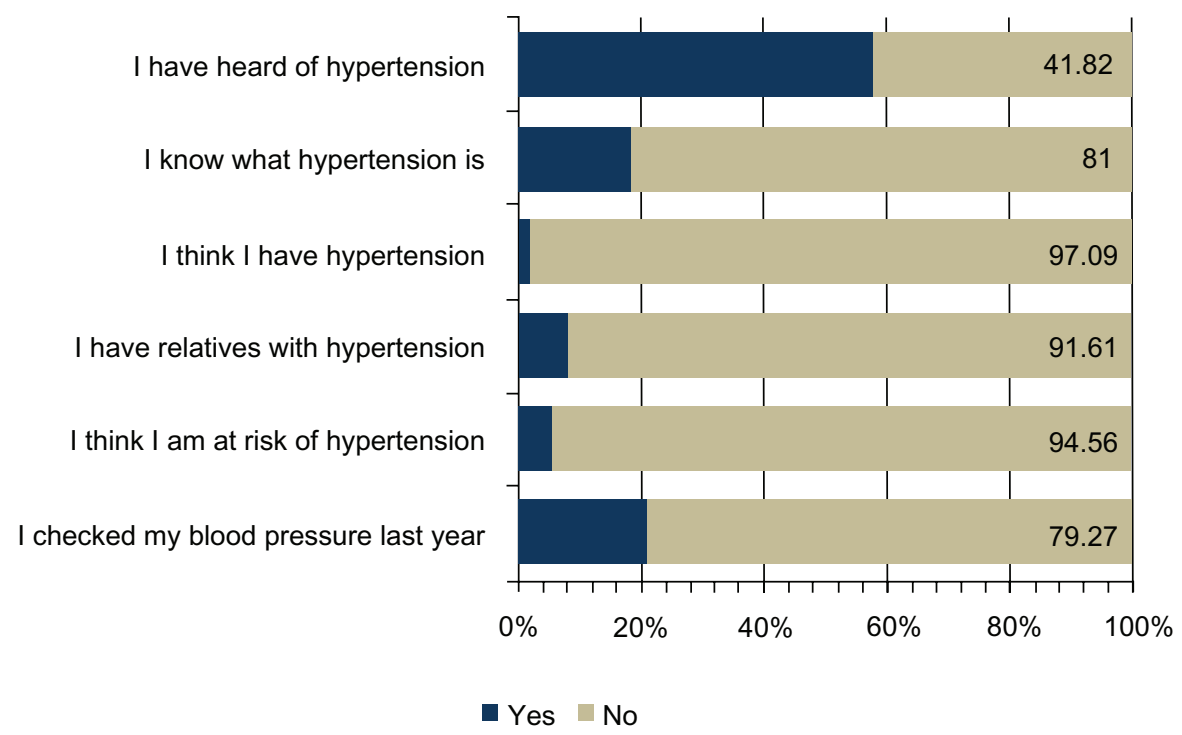

Figure 4 Assessment of awareness about hypertension in the Karen population.

Notes: The response rate was not $100 \%$ in all questionnaires. The man response rate was more than $93 \%$.

(15.10\%) of hypertension (blood pressure $\geq 140 / 90 \mathrm{mmHg}$ ) in the Karen community compared with the Thailand national prevalence of hypertension of $34 \%$ in $2008 .^{18}$ As already reported in the literature, high blood pressure becomes increasingly common with advancing age ${ }^{13}$ (Figure 1). The prevalence of overweight in the Karen population sample was $17.79 \%$, which is less than the Thailand national prevalence of $34.2 \%,{ }^{19}$ and reflects the physically active farming occupations of the study participants.

Other risk factors were also identified in our study sample. Alarmingly, the smoking rate was very high at $67.79 \%$, which is higher than Thailand's national smoking rate, both among men (76.23\% versus $39.8 \%)$ and women (61.93\% versus 3.4\%). ${ }^{17}$ Alcohol use was reported by half of the study population. These risk factors also contribute to the increasing burden of hypertension and consequent cardiovascular disease.

A similarly high smoking rate (88\%) has been reported for the Nicobarese aborigines in India in 2011, with the prevalence of alcohol consumption and overweight/obesity being $54 \%$ and $37 \%$, respectively, and a $50.5 \%$ reported prevalence for hypertension. ${ }^{20}$ Without appropriate intervention, the Karen community is heading towards a similar prevalence of hypertension.

We identified a considerable prevalence of prehypertension and prediabetes in the Karen community. ${ }^{21,22}$ Moreover, awareness of hypertension among already hypertensive individuals was very poor (Table 2). The high smoking rate identified could lead to hypertension and a substantial cardiovascular disease burden in the near future.
There has been a recent report of the benefits of restoring normal blood pressure at the stage of prehypertension in a developed setting. ${ }^{22}$ However, in a rural setting, lifestyle intervention would be a more feasible strategy to prevent hypertension in persons at risk. In the Karen community, the most prevalent risk behavior was smoking, followed by alcohol consumption (Figure 3). The prevalence rates for obesity and diabetes in this community were not very high. Moreover, most of the participants reported a physically active lifestyle (Figure 3). Therefore, an intervention strategy focused on tobacco control and smoking cessation is urgently needed, along with an observational study of smokers in the Karen community.

The findings of the current study indicate that awareness of hypertension was less than $50 \%$ among persons at risk, and most of those at risk of hypertension were not aware of their risk. Similar epidemiological findings of poor awareness have also been reported for rural populations in Thailand, China, and India, as well as neighboring Asian countries. ${ }^{23-26}$ To reverse the trend of increasing risk and

Table 4 Association of school education and health education about hypertension

\begin{tabular}{llll}
\hline $\begin{array}{l}\text { School } \\
\text { education }\end{array}$ & $\mathbf{n}$ & \multicolumn{2}{l}{$\begin{array}{l}\text { Answer "yes" to have you } \\
\text { ever heard of hypertension }\end{array}$} \\
\cline { 2 - 4 } & & $\%(\mathbf{n})$ & OR (95\% CI) \\
\hline No & 244 & $54.10(132)$ & 1.00 \\
Yes & 26 & $88.46(23)$ & $6.50(1.90-22.24)$ \\
\hline
\end{tabular}

Abbreviations: OR, odds ratio by multinomial logistic regression analysis; $\mathrm{Cl}$, confidence interval. 
prevent the consequences of hypertension and cardiovascular disease, community awareness should be promoted in a timely manner. ${ }^{23}$

\section{Awareness of hypertension and smoking versus school education}

Further analysis showed that health knowledge about hypertension was protective against smoking. The more people knew about hypertension, the less they tended to smoke (Table 3). Moreover, there was a significant association between level of school education and knowledge and awareness of hypertension (Table 4). This finding suggests an effective intervention for cardiovascular health promotion in the Karen community. Most of the study population lacked primary school education and could not read and write in the Thai language. Health education material needs to be provided in the native Karen language to reach the population at risk, including the elderly. Intervention to upgrade the literacy rate in these minority people would also be necessary. Health knowledge about hypertension and cardiovascular disease can be delivered in an educational program.

\section{Limitations}

Because this was a pilot study conducted with limited resources, it has some shortcomings. People in the study site villages live in clusters of houses on hilltops. Even though it was a community-based study, the participants were fit enough to walk to the study center for data collection, whereas those who were sick and bed-ridden could not attend. Moreover, advocates for health promotion are more likely to participate in such studies. These factors might have lead to an underestimation of the prevalence of hypertension and overestimation of health knowledge and awareness about the disease in this rural community. Further, the age distribution in the study contained a higher proportion of middle-age individuals, so this study finding would be interpreted in reference to its domain in the baseline characteristic table.

\section{Conclusion}

Despite the limitations, this study provides an insight to the epidemiological patterns of risk factors, risk behaviors, and risk awareness regarding hypertension and cardiovascular diseases in the rural Karen ethnic minority at the ThaiMyanmar border. Smoking is a major prevalent risk factor for hypertension in the Karen community. Awareness of hypertension in the population at risk was alarmingly low. Promoting public education in such rural communities would be beneficial for raising community awareness and changing health risk behaviors. The results of the current study may be useful for devising an interventional strategy for prevention of the cardiovascular disease epidemic in such rural communities.

\section{Authors' contributions}

Thaworn Lorga and Myo Nyein Aung were lead authors who designed the study. All authors contributed to data collection, data management, and the research process. Myo Nyein Aung analyzed the data, interpreted the results, and wrote the manuscript. All the authors reviewed and commented to finalize the manuscript.

\section{Disclosure}

The authors report no conflicts of interest in this work.

\section{References}

1. World Health Organization: Cardiovascular diseases: Key messages to protect heart health. 2011; Available from: http://www.who.int/ cardiovascular_diseases/en/. Accessed August 22, 2011.

2. Kusuma Y. Perceptions on hypertension among migrants in Delhi, India: a qualitative study. BMC Public Health. 2009;9(1):267.

3. Neiman A, Soh E, Sutan P. Karen cultural profile, 2008. Available from: http://ethnomed.org/culture/karen/karen-cultural-profile. Accessed October 20, 2011

4. Thai Hypertension Society. Guidelines in the treatment of hypertension, 2008. Available from: http://www.thaihypertension.org/2008guideline. pdf. Accessed April 1, 2012.

5. US Department of Health and Human Services. Hypertension and prehypertension, 2011. Available from: http://www.foh.hhs.gov/NYCU/ hypertension.asp. Accessed April 1, 2012.

6. Aekplakorn W, Bunnag P, Woodward M, et al. A risk score for predicting incident diabetes in the Thai population. Diabetes Care. 2006;29(8):1872-1877.

7. [No authors listed]. Diagnosis and classification of diabetes mellitus. Diabetes Care. 2004;27 Suppl 1:S5-S10.

8. Thaikruea L, Seetamanotch W, Seetamanotch S. Appropriate cutoff level of BMI for screening in Thai adults. J Med Assoc Thai. 2006;89(12):2123-2128.

9. Low S, Chin MC, Ma S, Heng D, Deurenberg-Yap M. Rationale for redefining obesity in Asians. Ann Acad Med Singapore. 2009;38(1):66-69.

10. World Health Organization. Global database on body mass index; BMI classification. Available from: http://www.who.int/bmi/index. jsp?introPage=intro_3.html. Accessed April 1, 2012.

11. Ross R, Berentzen T, Bradshaw AJ, et al. Does the relationship between waist circumference, morbidity and mortality depend on measurement protocol for waist circumference? Obes Rev. 2008;9(4):312-325.

12. Sliwa K, Stewart S, Gersh BJ. Hypertension: a global perspective. Circulation. 2011;123(24):2892-2896.

13. Whelton PK, He J, Muntner P. Prevalence, awareness, treatment and control of hypertension in North America, North Africa and Asia. J Hum Hypertens. 2004;18(8):545-551.

14. World Health Organization. Global status report on noncommunicable diseases, 2010. Available from: http://www.who.int/nmh/publications/ ncd_report2010/en/. Accessed April 1, 2012.

15. World Health Organization. Health statistics and health information systems: Global health risks, 2011. Available from: www.who.int/ healthinfo/global.../global_health_risks/en/index.html. Accessed April 1, 2012. 
16. World Health Organization. Global health observatory (GHO): risk factors, 2011. Available from: http://www.who.int/gho/ncd/risk_factors/ en/index.html. Accessed April 1, 2012.

17. World Health Rankings. Health Profile: Thailand, 2011. Available from: http://www.worldlifeexpectancy.com/country-health-profile/thailand. Accessed April 1, 2012.

18. World Health Organization. Raised blood pressure, 2008. Available from: http://gamapserver.who.int/gho/interactive_charts/ncd/risk factors/blood_pressure_prevalence/atlas.html. Accessed December 20, 2011.

19. World Health Organization. Overweight and obesity prevalence, 2011. Available from: http:/gamapserver.who.int/gho/interactive_ charts/ncd/risk_factors/overweight_obesity/atlas.html. Accessed December 20, 2011.

20. Manimunda SP, Sugunan AP, Benegal V, Balakrishna N, Rao MV, Pesala KS. Association of hypertension with risk factors and hypertension related behaviour among the aboriginal Nicobarese tribe living in Car Nicobar Island, India. Indian J Med Res. 2011;133(3):287-293.

21. Levitan EB, Song Y, Ford ES, Liu S. Is nondiabetic hyperglycemia a risk factor for cardiovascular disease?: a meta-analysis of prospective studies. Arch Intern Med. 2004;164(19):2147-2155.
22. Sipahi I, Swaminathan A, Natesan V, Debanne SM, Simon DI, Fang JC. Effect of antihypertensive therapy on incident stroke in cohorts with prehypertensive blood pressure levels. Stroke. 2012; 43(2):432-440.

23. Sun Z, Zheng L, Detrano R, et al. Incidence and predictors of hypertension among rural Chinese adults: results from Liaoning Province. Ann Fam Med. 2010;8(1):19-24.

24. Gupta R, Pandey RM, Misra A, et al. High prevalence and low awareness, treatment and control of hypertension in Asian Indian women. J Hum Hypertens. September 1, 2011. [Epub ahead of print.]

25. Howteerakul N, Suwannapong N, Sittilerd R, Rawdaree P. Health risk behaviours, awareness, treatment and control of hypertension among rural community people in Thailand. Asia Pac J Public Health. 2006;18(1):3-9.

26. Son PT, Quang NN, Viet NL, et al. Prevalence, awareness, treatment and control of hypertension in Vietnam-results from a national survey. J Hum Hypertens. 2012;26(4):268-280.
International Journal of General Medicine

\section{Publish your work in this journal}

The International Journal of General Medicine is an international peer-reviewed open-access journal that focuses on general and internal medicine, pathogenesis, epidemiology, diagnosis, monitoring and treatment protocols. The journal is characterized by the rapid reporting of reviews, original research and clinical studies across all disease areas.

\section{Dovepress}

A key focus is the elucidation of disease processes and management protocols resulting in improved outcomes for the patient.The manuscript management system is completely online and includes a very quick and fair peer-review system. Visit http://www.dovepress.com/ testimonials.php to read real quotes from published authors.

Submit your manuscript here: http://www.dovepress.com/international-journal-of-general-medicine-journal 